\title{
Controller Optimization Algorithm for a 12-pulse Voltage Source Converter based HVDC System
}

\author{
Ruchi Agarwal ${ }^{\dagger}$ and Sanjeev Singh*
}

\begin{abstract}
The paper presents controller optimization algorithm for a 12-pulse voltage source converter (VSC) based high voltage direct current (HVDC) system. To get an optimum algorithm, three methods namely conventional-Zeigler-Nichols, linear-golden section search (GSS) and stochastic-particle swarm optimization (PSO) are applied to control of 12 pulse VSC based HVDC system and simulation results are presented to show the best among the three. The performance results are obtained under various dynamic conditions such as load perturbation, non-linear load condition, and voltage sag, tapped load fault at points-of-common coupling (PCC) and single-line-to ground (SLG) fault at input AC mains. The conventional GSS and PSO algorithm are modified to enhance their performances under dynamic conditions. The results of this study show that modified particle swarm optimization provides the best results in terms of quick response to the dynamic conditions as compared to other optimization methods.
\end{abstract}

Keywords: PSO, GSS, VSC, HVDC, PQ

\section{Introduction}

Poor power quality at $\mathrm{AC}$ mains is closely associated with HVDC transmission system due to high involvement of power electronic equipment at points-of-common coupling (PCC). The HVDC system is the preferred option due to full controllability on power transmission. The voltage source converter is the latest choice in HVDC installation due to compact and light weighted design, short installation and commissioning period and low operating and maintenance cost. Besides these features, VSC has four quadrant control flexibility on power transmission [1-4]. However, the use of converters in HVDC system for purpose of rectification and inversion creates power quality (PQ) problems which are characterized by non-sinusoidal current, poor power factor, high displacement factor, and high crest value in $\mathrm{AC}$ mains current.

Due to practical relevance of PQ problems [3], a number of techniques have been proposed [5-9]. Among these, multipulse acts as an effective tool for harmonic mitigation. The multi pulse is developed on the basis of magnetics of three-phase converter system. It uses multi winding transformer at input of the rectifier which results higher number of pulse in DC output and more steps at input AC current, thereby makes the waveform near sinusoidal, thereby eliminates need of filters at the rectifier end and reduces problem at the inverter end [9]. There are number of multi pulse configurations, reported in the literatures

$\dagger$ Corresponding Author: Dept. of Electrical and Instrumentation Engineering, SLIET, Longowal, Punjab, India.

(agarwalruchi01@gmail.com)

* Dept. of Electrical and Instrumentation Engineering, SLIET, Longowal, Punjab. (sschauhan.sdl@gmail.com)

Received: December 14, 2015; Accepted: September 10, 2016
[6-7]. Since, HVDC system usually experiences number of dynamic situations such as load perturbation, non-linear load condition, voltage sag, and AC line fault, and it is very difficult to maintain power balance in DC link only with multi pulse technique. Therefore, it requires additional control which could make system 'robust' against dynamic situation.

The active wave shaping technique such pulse width modulation (PWM) is one of the effective option for controlling power in HVDC system under dynamic situations. The technique provides controlled duty cycles for self-commutated switches which in turn controls DClink power along with power quality at input $\mathrm{AC}$ mains [10-11]. The authors Arrillaga et al. have reported in text book [12] that the converters of HVDC system can be switched up to $2 \mathrm{kHz}$ frequency.

To get benefits of both techniques i.e. multipulse and active wave shaping technique, a 12-pulse converter, switched by PWM technique is proposed in this paper for power quality improvement in HVDC system. A 12-pulse configuration is selected for least component counts, thereby lesser control complexity as compared to other higher pulse converter configurations [6].

The paper is proposed for power transmission between long distanced AC interconnection for power balance. The power transmission influence by numbers of undesirable factors which effects capacity of power transmission, therefore, an additional control is required to maintain the target [13-14].

The controller used here is proportional-integral (PI) controller and if it is optimized, it provides full control over long distance power transmission. A number of optimization methods are reported in literatures, seminars, 
text books etc [15-24]. Among these, GSS and PSO techniques showed best results in many optimization problems $[23,24]$. The PSO is used for controlling VSC based HVDC system [24], however, AC filters are utilized to control power quality issues. Traditionally, Ziegler Nichols approach is used for controller tuning which is based on practical methodology but may not get optimal solution [20].

Therefore, optimized control using three different approaches i.e. conventional Zeigler Nichols, modified golden section search and modified particle swarm optimization are subjected to 12-pulse VSC based HVDC system for power quality improvement and comparative simulation results are presented to show the best among three.

\section{Power Quality Controller}

The schematic diagram and power quality controller of HVDC system are shown in Fig. 1. The system data are given in Appendix-1. The inductor and DC-link capacitor are significant components in designing of VSC based HVDC system, therefore, selection of component ratings are explained in Appendix-2.

The PQ indices i.e. total harmonic distortion (THD), power factor $(\mathrm{PF})$ and $\mathrm{DC}$-link voltage ripple $\left(\mathrm{V}_{\mathrm{rp}}\right)$ are governed by voltage and current controller, thereby named as power quality controller in this work. The controller

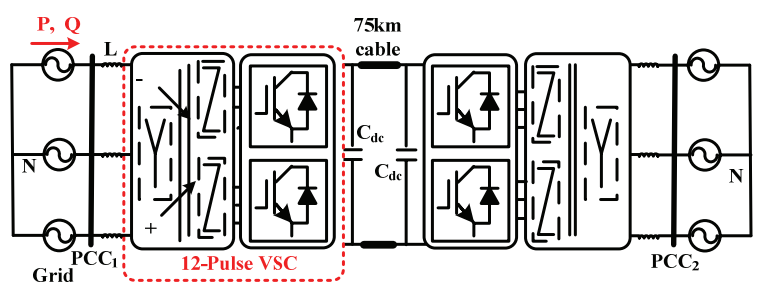

(a)

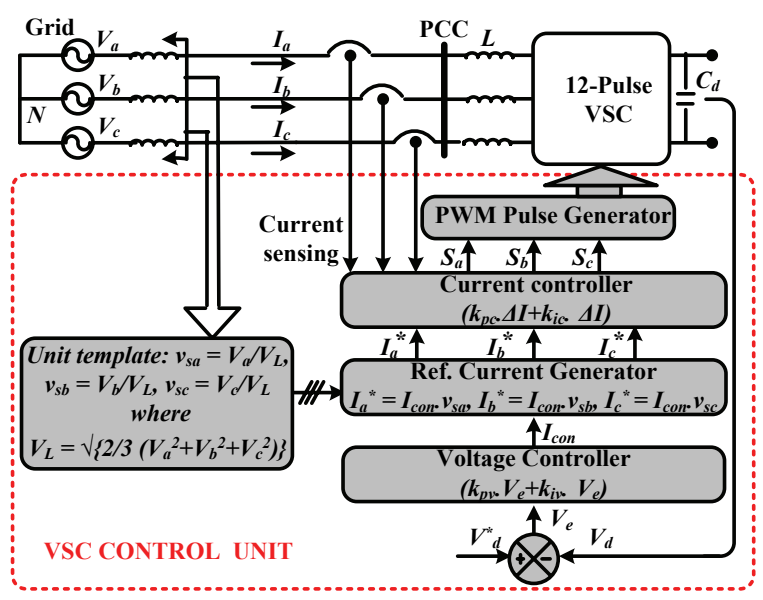

(b)

Fig. 1. Schematic diagram of (a) 12-pulse VSC based HVDC system; (b) power quality controller controls DC-link voltage as well as wave shape of input AC mains current.

The control approach initializes with sensing the DClink voltage and compares with desired DC-link voltage, in this work $190 \mathrm{kV}$, therefore modulation index $(\mathrm{m})$ is maintained 0.85 , obtained by control equation $\mathrm{m}=$ $2 \sqrt{ } 2 \mathrm{~V}_{\mathrm{LL}} / \sqrt{ } 3 \mathrm{~V}_{\mathrm{d}}$ [21], where $\mathrm{V}_{\mathrm{LL}}$ is secondary side transformer voltage. The obtained voltage error is passed through PI based voltage controller to get control signal. The control signal is multiplied with unit template of supply voltage, results three phase current references. The three phase referenced currents are compared with sensed three phase currents to measure current errors. Further, the current errors are passed through the current controller which results modulating signals. The modulating signals are compared with triangular carrier waveforms which generates PWM signals for VSC switches.

Hence, the system output depends on the controller gains, therefore, an attempt is made for selection of optimum controller gain by the proposed approaches.

\section{Proposed Optimization Techniques}

There are number of optimization techniques reported in the literatures, accordingly the optimization techniques are categorized into two ways, namely deterministic and stochastic approach as shown in Fig. 2. The deterministic technique relies on linear algebra and based on computation of the gradients. It requires lower number of function variables to reach the optimum solution. The golden section search involves in this category. This approach is simple and easily implementable to the optimization problem, therefore this approach is proposed with some modifications. As the GSS approach operates with known parameters only with some specific rules whereas stochastic technique is based on heuristic approach i.e the parameters are described by randomly or probabilistically. The GSS and PSO are proposed in this paper for controller tuning. Traditionally, Ziegler-Nichols is used for controller tuning which is dependent on number of factors such as rule of thumb, gausses, an intuitive judgment, stereotyping, and common sense etc [20].

The operation of all techniques i.e. conventional ZeiglerNichol approach, linear-GSS, and stochastic-PSO are discussed in details in the subsequent section. The detail includes power quality problem formulation, modifications to the conventional approaches and implementation of the

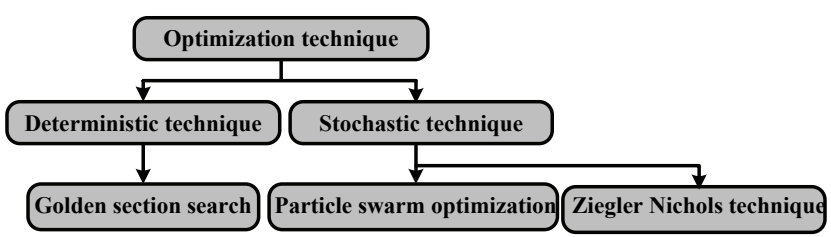

Fig. 2. Optimization techniques 
Table 1. Rules of Ziegler-Nichols approach

\begin{tabular}{c|c|c|c}
\hline Controller type & $\mathrm{k}_{\mathrm{p}}$ & $\mathrm{T}_{\mathrm{i}}$ & $\mathrm{T}_{\mathrm{d}}$ \\
\hline $\mathrm{P}$ & $0.5\left(\mathrm{k}_{\mathrm{cr}}\right)$ & $\infty$ & 0 \\
\hline $\mathrm{PI}$ & $0.45\left(\mathrm{k}_{\mathrm{cr}}\right)$ & $\left(\mathrm{T}_{\mathrm{cr}}\right) / 12$ & 0 \\
\hline PID & $0.6\left(\mathrm{k}_{\mathrm{rr}}\right)$ & $0.5\left(\mathrm{~T}_{\mathrm{rr}}\right)$ & $0.125\left(\mathrm{~T}_{\mathrm{cr}}\right)$ \\
\hline
\end{tabular}

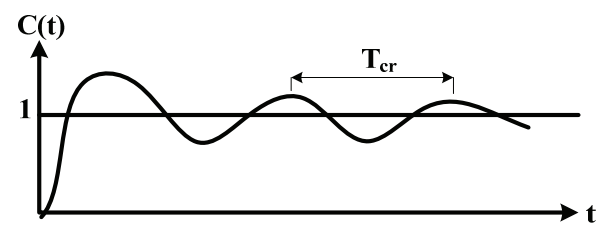

Fig. 3 System response

proposed approaches to the proposed case.

\subsection{Conventional zeigler-nichols approach}

The Zeigler Nichols approach tunes PI controller gain according to the dynamic response characteristic. It mainly concentrates on proportional gain tuning, accordingly integral controller gain is tuned. Initially, integral controller is deactivated, the proportional controller is reset by its value minimum and slowly increases up to that value in which the system starts sustained oscillations. Further, an offset error between desired and measured value is mitigated by integral gain tuning.

Fig. 3 shows system behavior under dynamic condition, frequency of sustained oscillation is considered as $1 / \mathrm{T}_{\mathrm{cr}}$ and controller gain is known as critical gain $\mathrm{k}_{\mathrm{cr}}$. Table 1 presents some rules to calculate the actual controller gains [22]. The proportional gain is calculated as done in Table 1 wherein the integral gain is measured as,

$$
\mathrm{k}_{\mathrm{i}}=1 / \mathrm{T}_{\mathrm{i}}
$$

\subsection{Proposed golden section search approach}

The golden section search is generally applied to unconstrained single objective problem. It searches optimal point by successive narrowing specified limit of control variable range. In this paper, the traditional GSS is modified to design for constrained multi objective problem. Four control variables are subjected under GSS operation to search for optimal point of the controller gains.

The multi objective problem is characterized by power quality indices which is composed of current harmonic distortion, power factor and DC-link voltage ripple in the HVDC system considered as fitness function. In the multi objective problem, power factor needs to improve; therefore, objective function of power factor is redesigned for multi objective problem which is calculated as,

$$
\begin{aligned}
\text { Power factor }(\mathrm{PF}) & =\text { Input Power } / 3 \mathrm{~V}_{\mathrm{rms}} \mathrm{I}_{\mathrm{rms}} \\
\mathrm{f}_{1} & =-\mathrm{PF}
\end{aligned}
$$

where $\mathrm{V}_{\mathrm{rms}}$ : RMS supply voltage; $\mathrm{I}_{\mathrm{rms}}$ : RMS supply current

The harmonic mitigation is another prime objective which is formulated as,

$$
\begin{gathered}
\mathrm{THD}_{\mathrm{i}}=\sqrt{ }\left\{\left(\mathrm{I}_{\text {rms }}^{2}-\mathrm{I}^{2}{ }_{0}\right) / \mathrm{I}_{0}\right\} \\
\mathrm{f}_{2}=\mathrm{THD}_{\mathrm{i}}
\end{gathered}
$$

where $\mathrm{I}_{0}$ is fundamental current of the supply.

The DC-link voltage ripple is calculated as,

$$
\begin{aligned}
\left|V_{\mathrm{rp}}\right| & =\mathrm{V}_{\mathrm{d}}^{*}-\mathrm{V}_{\mathrm{d}} \\
\mathrm{f}_{3} & =\left|\mathrm{V}_{\mathrm{rp}}\right|
\end{aligned}
$$

where $\mathrm{V}_{\mathrm{d}}^{*}$ is referenced DC-link voltage and $\mathrm{V}_{\mathrm{d}}$ is measured DC-link voltage.

The equal weightage is given to each objective function to formulate multi objective problem, therefore, $\mathrm{w}_{1}=\mathrm{w}_{2}=$ $\mathrm{w}_{3}=1 / 3$ are considered in the fitness function $(\mathrm{F})$.

$$
\mathrm{F}=\mathrm{w}_{1} \cdot \mathrm{f}_{1}+\mathrm{w}_{2} \cdot \mathrm{f}_{2}+\mathrm{w}_{3} \cdot \mathrm{f}_{3}
$$

Some inequality constraints are imposed to the fitness function which must be satisfied in the search process,

$$
\begin{gathered}
\mathrm{THD}_{\mathrm{i}} \leq 5 \% \\
\mathrm{PF}>0.8 \\
\mathrm{~V}_{\text {rpmax }}<5 \%
\end{gathered}
$$

Hence, PQ considered multi objective problem is designed with inequality constraints.

Since, the PQ indices are governed by the voltage and current controller, the controller gains i.e. $\mathrm{k}_{\mathrm{pv}}, \mathrm{k}_{\mathrm{iv}}, \mathrm{k}_{\mathrm{pc}}$ and $\mathrm{k}_{\mathrm{ic}}$ are used as control variables in the proposed GSS technique. All controller gains are operated under GSS sequentially $\left(\mathrm{k}_{\mathrm{ic}} \gg \mathrm{k}_{\mathrm{iv}} \gg \mathrm{k}_{\mathrm{pv}}\right)$ except $\mathrm{k}_{\mathrm{pc}}$ as it varies linearly.

The search starts with initialization of wide range of the controller gain, golden ratio $(\lambda)$ [23], generation counter etc. The nomenclatures i.e. $\mathrm{kL}$ and $\mathrm{kU}$ are used for lower and upper range of each control variables respectively. Two intermediate points $\left(\mathrm{x}_{1} \& \mathrm{x}_{2}\right)$ are selected between lower and upper range of the control variable which are estimated as,

$$
\begin{aligned}
& \mathrm{x}_{1}=\mathrm{k}_{\mathrm{L}}+\mathrm{a} \\
& \mathrm{x}_{2}=\mathrm{k}_{\mathrm{U}}-\mathrm{a}
\end{aligned}
$$

where $\mathrm{a}=\lambda \times\left(\mathrm{k}_{\mathrm{U}}-\mathrm{k}_{\mathrm{L}}\right)$

All four points i.e $\mathrm{k}_{\mathrm{L}}, \mathrm{x}_{1}, \mathrm{x}_{2}, \mathrm{k}_{\mathrm{U}}$ are considered as GSS points in this search. The GSS points update their positions either Type-I or Type-II contraction based on location of the expected optimal point as shown in Fig. 4(a) and complete search process is explained by Fig. 4(b).

Rules for Type-I contraction,

$$
\mathrm{k}_{\mathrm{L}}{ }^{\prime}=\mathrm{k}_{\mathrm{L}} ; \mathrm{k}_{\mathrm{U}}{ }^{\prime}=\mathrm{x}_{1} ; \mathrm{x}_{1}{ }^{\prime}=\mathrm{x}_{2} ; \mathrm{x}_{2}{ }^{\prime}=\mathrm{k}_{\mathrm{U}}-\mathrm{a}
$$




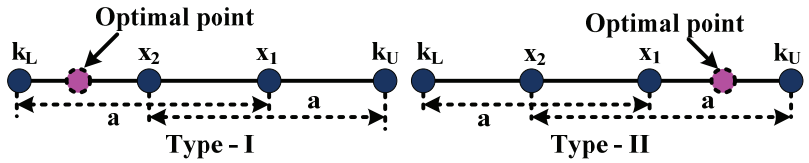

(a)

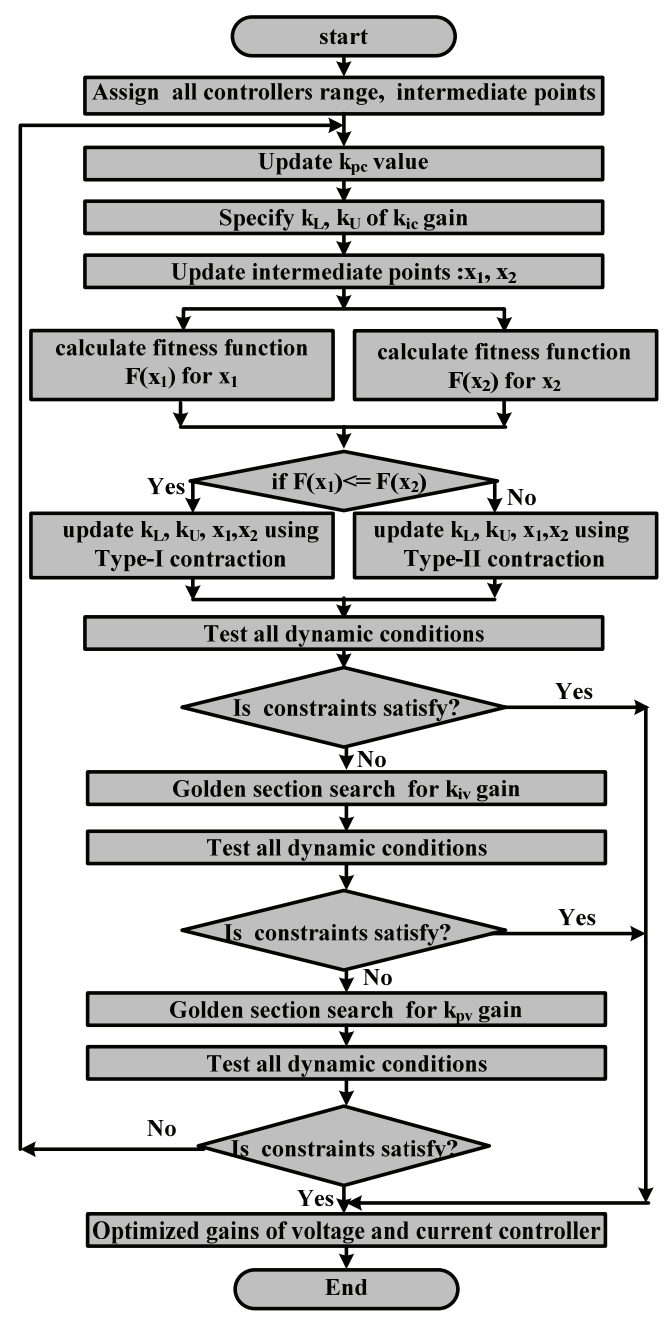

(b)

Fig. 4. (a) Type-I and Type-II contraction; (b) proposed GSS approach

Rules for Type-II contraction,

$$
\mathrm{k}_{\mathrm{L}}{ }^{\prime}=\mathrm{x}_{2} ; \mathrm{k}_{\mathrm{U}}{ }^{\prime}=\mathrm{k}_{\mathrm{U}} ; \quad \mathrm{x}_{2}{ }^{\prime}=\mathrm{x}_{1} ; \mathrm{x}_{1}{ }^{\prime}=\mathrm{k}_{\mathrm{L}}+\mathrm{a}
$$

where $\mathrm{k}_{\mathrm{L}}{ }^{\prime}, \mathrm{k}_{\mathrm{U}}, \mathrm{x}_{1}$, , and $\mathrm{x}_{2}$ ' are updated points.

The single time contraction either Type-I or Type-II is programmed in a generation. Initially, controller gains are specified with lower value of the controller gain i.e. $\mathrm{k}_{\mathrm{L}}$. However, mean value is calculated between $\mathrm{x}_{1}$ and $\mathrm{x}_{2}$ points of the GSS operated gain to test dynamic conditions. All four controller gains are used to test all dynamic conditions i.e. load perturbation, non-linear load, voltage sag, tapped load fault, single line to ground fault at input AC mains including GSS operated controller gain in each generation. If all dynamic conditions are satisfied under

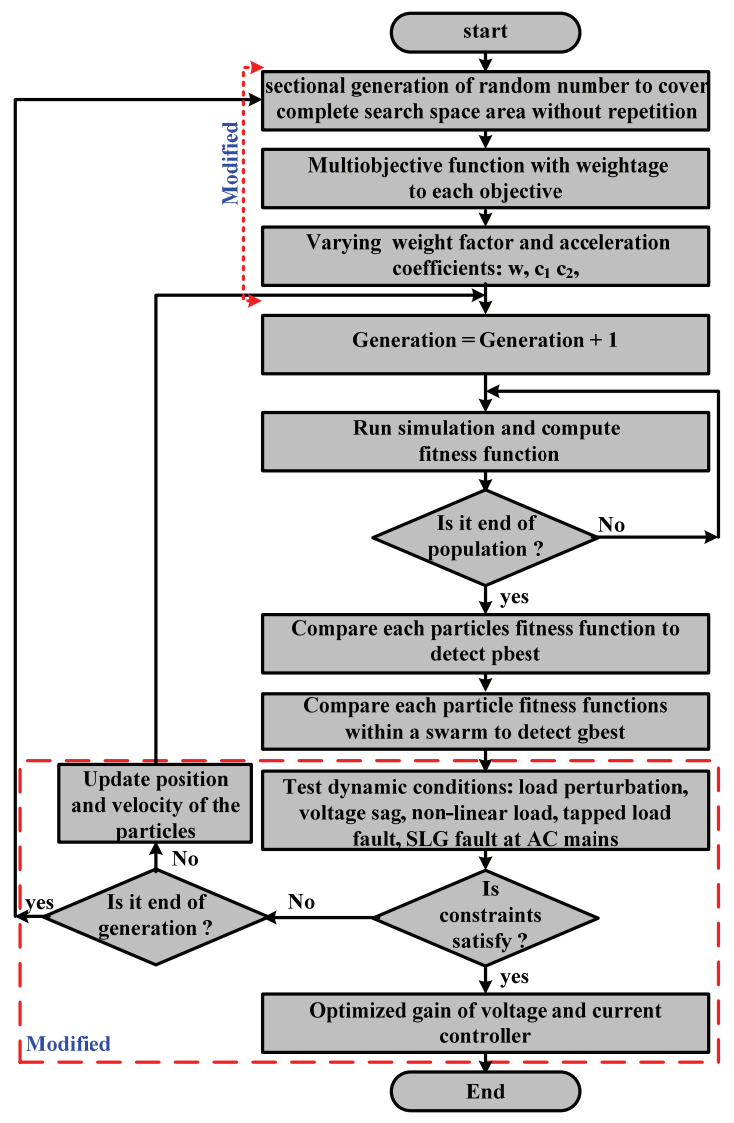

Fig. 5. Proposed PSO approach

specified constraints, the program terminates otherwise enters to the next generation. The proposed approach selects common optimal point of the controller gains for various dynamic conditions by satisfying all imposed constraints.

\subsection{Proposed particle swarm optimization approach}

The PSO approach is proposed with some modifications to eliminate the drawbacks found in conventional PSO approach such as limited search area, long processing time.

All modifications are highlighted by the flow chart as presented in Fig. 5. The first modification is to generate random numbers in the search space. Traditionally, random numbers are generated by the pseudo-random number generator (PRNGs) which generates usually single digit number in base 10 as decimal number with repetitions. In generator, mathematical formula or pre calculated tables are internally programmed which outputs random number, however it appears as a random, but according to rigorous definition they are not actually random [17]. This drawback is eliminated by sectional generation of random numbers in this work. The large search space area is divided into small subsections and random numbers are generated in each subsection and then collectively applied all numbers to the problem, thereby explores complete search space without repetition of the numbers. 
The dynamic behavior of the particles in PSO technique is governed by two control equations,

$$
\begin{aligned}
& \mathrm{V}_{\mathrm{i}}(\mathrm{t}+1)=\mathrm{wV}_{\mathrm{i}}(\mathrm{t})+\mathrm{c}_{1} \mathrm{r}_{1}\left(\operatorname{pbest}_{\mathrm{i}}(\mathrm{t})-\mathrm{X}_{\mathrm{i}}(\mathrm{t})\right)+\mathrm{c}_{2} \mathrm{r}_{2}\left(\operatorname{gbest}(\mathrm{t})-\mathrm{X}_{\mathrm{i}}(\mathrm{t})\right) \\
& \mathrm{X}_{\mathrm{i}}(\mathrm{t}+1)=\mathrm{X}_{\mathrm{i}}(\mathrm{t})+\mathrm{V}_{\mathrm{i}}(\mathrm{t}+1)
\end{aligned}
$$

where $\mathrm{V}_{\mathrm{i}}(\mathrm{t})=$ current velocity; $\mathrm{V}_{\mathrm{i}}(\mathrm{t}+1)=$ updated velocity; $\mathrm{X}_{\mathrm{i}}(\mathrm{t})=$ current position; $\mathrm{X}_{\mathrm{i}}(\mathrm{t}+1)=$ updated position; pbest $_{\mathrm{i}}=$ particle best; gbest $_{\mathrm{i}}=$ particle best in the swarm. The variables namely $r_{1}, r_{2}$ are random numbers, generated between 0 and 1 . The variable, $\mathrm{w}$ is weighting factor and $\mathrm{c}_{1}$, $c_{2}$ are acceleration coefficients and they are generally used with fixed values in conventional PSO search approach. However, H.C. Watson suggested that the variation of weighting factor $(\mathrm{w})$ from high value to low value and time varying behavior of the acceleration coefficients $\left(c_{1}\right.$ and $\left.c_{2}\right)$ in PSO approach results best performance in most of the applications [17]. Therefore, parametric variations (w, $\mathrm{c}_{1}$ and $\mathrm{c}_{2}$ ) are proposed in the proposed work.

The parameters are varied as,

$$
\begin{gathered}
\mathrm{c}_{1}=2.5-2 \times\left(\mathrm{G}^{*} / \mathrm{G}_{\max }\right) \\
\mathrm{c}_{2}=0.5+2 \times\left(\mathrm{G}^{*} / \mathrm{G}_{\max }\right) \\
\mathrm{w}=\mathrm{w}_{\max }-\left\{\left(\mathrm{w}_{\max }-\mathrm{w}_{\min }\right) \times \mathrm{G}^{*}\right\} / \mathrm{G}_{\max }
\end{gathered}
$$

where $\mathrm{G}^{*}=$ current generation; $\mathrm{G}_{\max }=$ maximum generation and $\mathrm{w}_{\max }, \mathrm{w}_{\min }$ are maximum and minimum value of the weighting factor which are considered as 0.9 and 0.4 respectively [19].

In conventional $\mathrm{PSO}$, the program terminates after fully convergence of all particles, thereby results long processing time. Therefore, termination criteria is modified in the proposed PSO approach, the global best value, obtained in each generation is tested for dynamic conditions, if all dynamic conditions are satisfied under specified constraints, the program terminates and gets optimized output otherwise particles update with their new positions and velocities for the next generation for seeking optimal value.

The proposed PSO approach achieves common operating point for the controllers for various dynamic conditions.

\section{Results and Discussion}

\subsection{Performance evaluation using zeigler nichols approach}

The power quality controller has voltage and current controller, initially, the current controller is deactivated. The voltage controller is tuned under load perturbation condition as shown in Fig. 6.

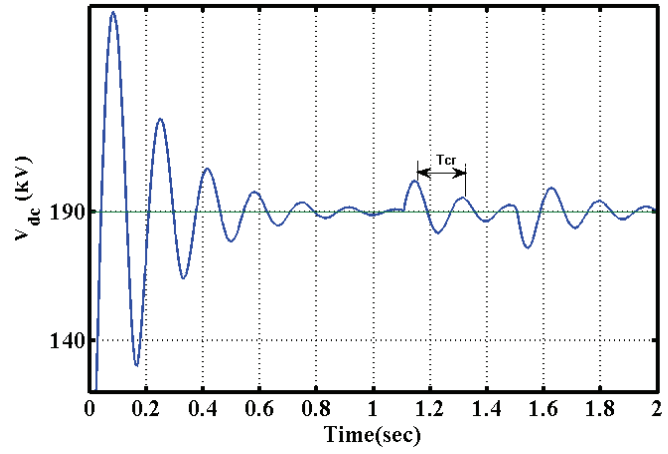

(a)

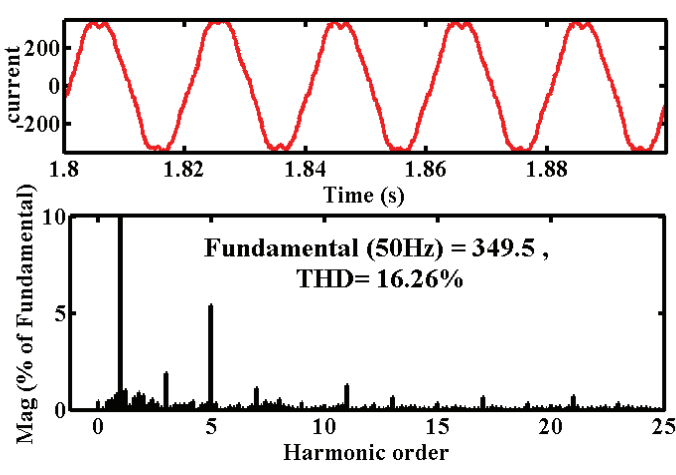

(b)

Fig. 6. (a) DC-link response; (b) current harmonic distortion with voltage controller

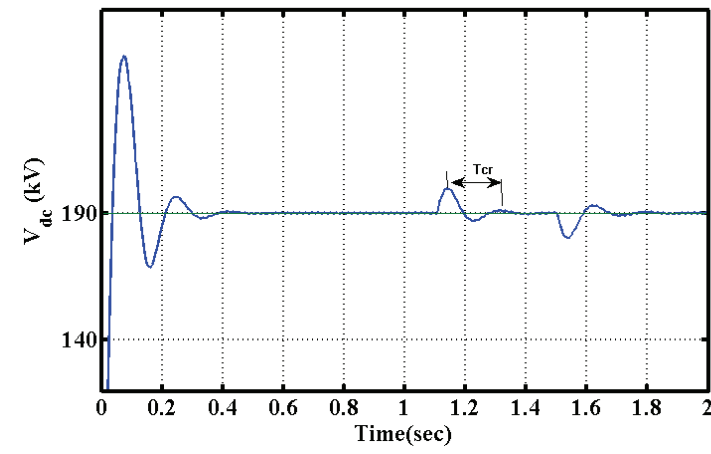

(a)

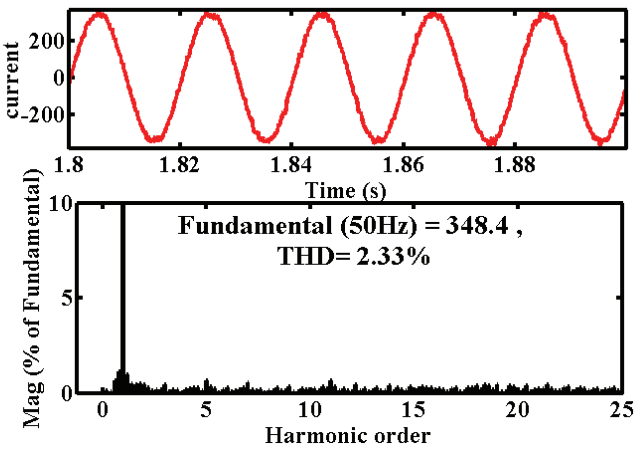

(b)

Fig. 7. (a) DC-link response; (b) current harmonic distortion with voltage and current controller 
The controller gain, $\mathrm{k}_{\mathrm{pv}}$ and $\mathrm{k}_{\mathrm{iv}}$ are calculated as,

$\mathrm{k}_{\mathrm{pv}}=0.45 \times\left(\mathrm{k}_{\mathrm{cr}}\right)=0.54$

$\mathrm{T}_{\mathrm{i}}=(1 / 12) \times\left(\mathrm{T}_{\mathrm{cr}}\right)=0.02390$, hence $\mathrm{k}_{\mathrm{iv}}=1 / 0.0239=41.81$

where $\mathrm{k}_{\mathrm{cr}}$ and $\mathrm{T}_{\mathrm{cr}}$ are measured 1.2 and 0.287 value respectively using rules mentioned in Table 1.

The current distortion is measured as shown in Fig. 6(b), however it exploits the International standard [4], thereafter, the current controller is introduced. The measurement of $\mathrm{k}_{\mathrm{cr}}$ and $\mathrm{T}_{\mathrm{cr}}$ for current controller are measured with similar manner, keeping same value of voltage controller, as calculated above. $\mathrm{k}_{\mathrm{cr}}$ and $\mathrm{T}_{\mathrm{cr}}$ are measured 0.64 and 5.45 respectively,

$$
\begin{aligned}
& \mathrm{k}_{\mathrm{pc}}=0.29 \text { and } \mathrm{T}_{\mathrm{i}}=0.454 \\
& \mathrm{k}_{\mathrm{ic}}=1 / \mathrm{T}_{\mathrm{i}}=2.2
\end{aligned}
$$

The current harmonic distortion is measured $2.33 \%$ which satisfies clean power standard as shown in Fig. 7.

With similar procedure, voltage and current controller

Table 2. Controller gains obtained by Ziegler-Nichols approach

\begin{tabular}{ccccc}
\hline Dynamic & \multicolumn{2}{c}{ Voltage controller gain } & \multicolumn{2}{c}{ Current controller gain } \\
\cline { 2 - 5 } Conditions & $\mathrm{k}_{\mathrm{pv}}$ & $\mathrm{k}_{\mathrm{iv}}$ & $\mathrm{k}_{\mathrm{pc}}$ & $\mathrm{k}_{\mathrm{ic}}$ \\
\hline Load perturbation & 0.54 & 41.8 & 0.29 & 2.2 \\
Non-linear load & 0.144 & 36.8 & 0.4 & 3.9 \\
Voltage sag & 0.19 & 28.5 & 0.25 & 1.6 \\
Tapped load fault & 0.54 & 27.9 & 0.82 & 6.5 \\
Fault at phase A & 0.72 & 19.32 & 0.21 & 2.6 \\
\hline
\end{tabular}

gain are obtained for other dynamic conditions such as voltage sag, non-linear load, tapped load fault at PCC and SLG fault at input AC mains. The obtained controller gains are presented in Table 2 .

\subsection{Performance evaluation using proposed GSS approach}

In proposed GSS approach, the controller gains are varied sequentially $\left(\mathrm{k}_{\mathrm{pc}} \gg \mathrm{k}_{\mathrm{ic}} \gg \mathrm{k}_{\mathrm{iv}} \gg \mathrm{k}_{\mathrm{pv}}\right)$. Initially, wide range of controller gains are taken i.e. $1<\mathrm{k}_{\mathrm{pv}}<60,1<\mathrm{k}_{\mathrm{iv}}<250$, $0.01<\mathrm{k}_{\mathrm{pc}}<60$, and $0.01<\mathrm{k}_{\mathrm{ic}}<100$, however in $10.345 \mathrm{hr}$, small portion of controller gain could be explored, therefore, to show effectiveness of the proposed scheme, small portion of controller gains with some guesses are selected.

Fig. 8 shows optimized power quality results, however Table 3 shows PQ results obtained under complete GSS approach. From $1^{\text {st }}$ to $20^{\text {th }}$ generation, current harmonic distortion for all dynamic conditions are above $5 \%$, only non-linear load dynamic condition could satisfy Internationally prescribed limit on $25^{\text {th }}$ generation. It maintains up to $45^{\text {th }}$ generation. The search continues for seeking of better results, two dynamic conditions, namely load perturbation and non-linear load satisfy constrained limits. Further, on $60^{\text {th }}$ generation, all dynamic conditions give improved results with $\mathrm{THD}_{\mathrm{i}}$ less than $5 \%$ except SLG fault at phase A. Finally, on $67^{\text {th }}$ generation, all dynamic conditions are satisfied under all imposed constraints.

Fig. 9(a) shows voltage controller gain variation, on $5^{\text {th }}$ generation, it gets 3.8 value, however it changes during $10^{\text {th }}-30^{\text {th }}$ generation, again it retains on $35^{\text {th }}$ generation and
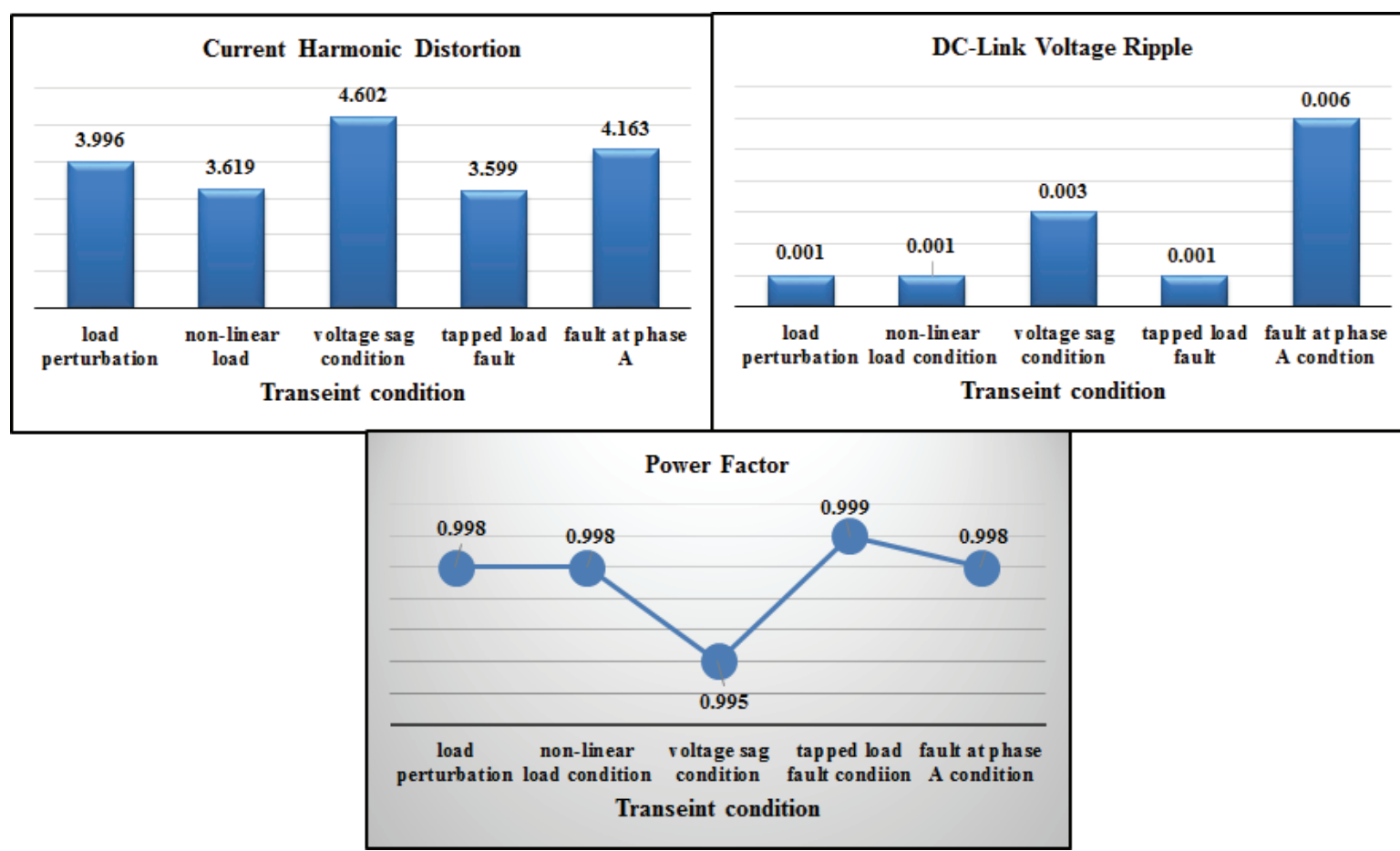

Fig. 8. Power quality indices with optimized controller gain using GSS approach 
Table 3. PQ results under proposed GSS approach

\begin{tabular}{|c|c|c|c|c|c|c|c|c|c|c|c|c|c|c|c|}
\hline \multicolumn{16}{|c|}{ Controller search range: $1<\mathrm{k}_{\mathrm{pv}}<10,100<\mathrm{k}_{\mathrm{iv}}<200,1<\mathrm{k}_{\mathrm{pc}}<12,50<\mathrm{k}_{\mathrm{ic}}<100$} \\
\hline \multirow{3}{*}{ Gen } & \multicolumn{15}{|c|}{ Different Dynamic Conditions } \\
\hline & \multicolumn{3}{|c|}{ Load perturbation } & \multicolumn{3}{|c|}{ Non-linear load } & \multicolumn{3}{|c|}{ Voltage sag } & \multicolumn{3}{|c|}{ Tapped load fault } & \multicolumn{3}{|c|}{ SLG at phase $\mathrm{A}$} \\
\hline & $\mathrm{THD}_{\mathrm{i}}(\%)$ & $\mathrm{PF}$ & $\mathrm{V}_{\mathrm{rp}}(\mathrm{pu})$ & $\mathrm{THD}_{\mathrm{i}}(\%)$ & $\mathrm{PF}$ & $\mathrm{V}_{\mathrm{rp}}(\mathrm{pu})$ & $\mathrm{THD}_{\mathrm{i}}(\%)$ & $\mathrm{PF}$ & $\mathrm{V}_{\mathrm{rp}}(\mathrm{pu})$ & $\mathrm{THD}_{\mathrm{i}}(\%)$ & $\mathrm{PF}$ & $\mathrm{V}_{\mathrm{rp}}(\mathrm{pu})$ & $\mathrm{THD}_{\mathrm{i}}(\%)$ & $\mathrm{PF}$ & $\mathrm{V}_{\mathrm{rp}}(\mathrm{pu})$ \\
\hline 1 & 11.017 & 0.997 & 0.004 & 8.57 & 0.981 & 0.014 & 10.648 & 0.984 & 0.001 & 10.662 & 0.99 & 0.004 & 10.919 & 0.989 & 0.004 \\
\hline 5 & 9.133 & 0.996 & 0.003 & 7.906 & 0.995 & 0.001 & 9.808 & 0.996 & 0.001 & 9.403 & 0.996 & 0.001 & 9.922 & 0.998 & 0.004 \\
\hline 10 & 8.798 & 0.993 & 0.001 & 6.799 & 0.991 & 0.001 & 8.707 & 0.998 & 0.001 & 7.97 & 0.998 & 0.002 & 9.815 & 0.998 & 0.009 \\
\hline 15 & 7.761 & 0.997 & 0.001 & 6.027 & 0.998 & 0.002 & 7.157 & 0.992 & 0.002 & 8.391 & 0.999 & 0.003 & 10.847 & 0.998 & 0.008 \\
\hline 20 & 6.304 & 0.992 & 0.001 & 6.358 & 0.995 & 0.001 & 7.024 & 0.997 & 0.003 & 6.806 & 0.998 & 0.001 & 9.149 & 0.998 & 0.009 \\
\hline 25 & 6.925 & 0.996 & 0.002 & 4.912 & 0.992 & 0.001 & 6.286 & 0.997 & 0.001 & 6.265 & 0.999 & 0.001 & 7.973 & 0.998 & 0.009 \\
\hline 30 & 6.251 & 0.998 & 0.001 & 4.91 & 0.994 & 0.002 & 6.79 & 0.998 & 0.001 & 6.095 & 0.999 & $\begin{array}{l}0.001 \\
\end{array}$ & 8.373 & 0.998 & 0.01 \\
\hline 35 & 6.114 & 0.998 & 0.001 & 4.703 & 0.998 & 0.001 & 5.716 & 0.998 & 0.001 & 5.752 & 0.997 & 0.002 & 6.781 & 0.998 & 0.007 \\
\hline 40 & 5.737 & 0.999 & 0.003 & 4.251 & 0.996 & 0.001 & 5.973 & 0.997 & 0.001 & 5.189 & 0.999 & 0.001 & 6.54 & 0.998 & 0.007 \\
\hline 45 & 5.029 & 0.999 & 0.002 & 4.049 & 0.996 & 0.001 & 5.372 & 0.997 & 0.001 & 5.434 & 0.997 & 0.003 & 6.848 & 0.998 & 0.009 \\
\hline 50 & 4.765 & 0.998 & 0.004 & 4.522 & 0.997 & 0.001 & 5.079 & 0.997 & 0.003 & 5.117 & 0.996 & 0.001 & 6.207 & 0.998 & 0.01 \\
\hline 55 & 5.091 & 0.999 & 0.002 & 3.61 & 0.998 & 0.001 & 4.666 & 0.996 & 0.002 & 4.775 & 0.994 & 0.001 & 4.426 & 0.998 & 0.006 \\
\hline 60 & 4.865 & 0.996 & 0.001 & 3.005 & 0.998 & 0.002 & 4.42 & 0.995 & $\begin{array}{l}0.001 \\
\end{array}$ & 4.764 & 0.996 & 0.001 & 5.9 & 0.998 & 0.007 \\
\hline 65 & 4.063 & 0.997 & 0.001 & 3.561 & \begin{tabular}{|l|l}
0.998 \\
\end{tabular} & 0.002 & 4.198 & 0.994 & 0.001 & 4.334 & 0.998 & 0.002 & 5.252 & 0.998 & 0.008 \\
\hline 67 & 3.996 & 0.998 & 0.001 & 3.619 & 0.998 & 0.001 & 4.602 & 0.995 & 0.003 & 3.599 & 0.999 & 0.001 & 4.163 & 0.998 & 0.006 \\
\hline
\end{tabular}

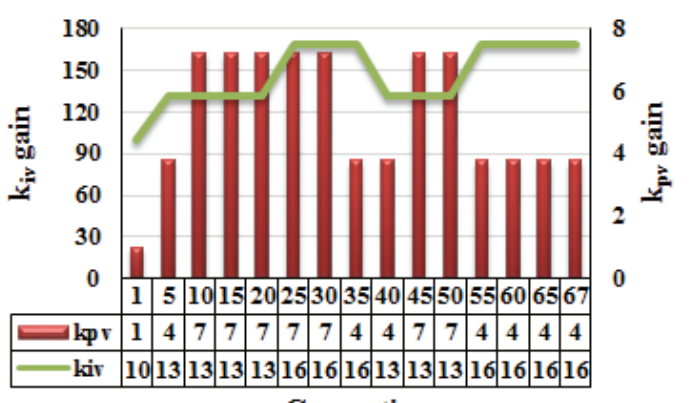

Generation

(a)

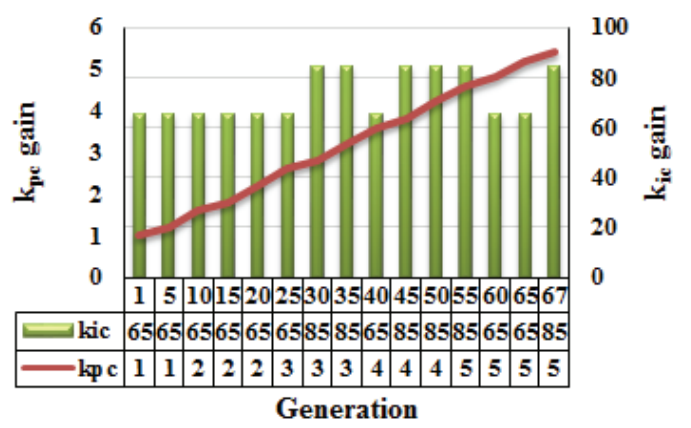

(b)

Fig. 9. (a) Variation of voltage controller gain w.r.t. generation; (b) Variation of current controller gain w.r.t. generation

maintains up to $40^{\text {th }}$ generation. By coordinating with integral gain, $\mathrm{k}_{\mathrm{pv}}$ changes, however, on $50^{\text {th }}$ generation, $\mathrm{k}_{\mathrm{pv}}$ and $\mathrm{k}_{\mathrm{iv}}$ gains settle down and gets optimized value 3.8 and 169 respectively.

Fig. 9(b) reveals current controller gain variation. The integral gain i.e. $\mathrm{k}_{\mathrm{ic}}$ is subjected GSS operation and toggles within 65 and 85 value. The $\mathrm{k}_{\mathrm{pc}}$ changes value linearly. The $\mathrm{k}_{\mathrm{ic}}$ gain starts with 65 value and remains same up to $25^{\text {th }}$

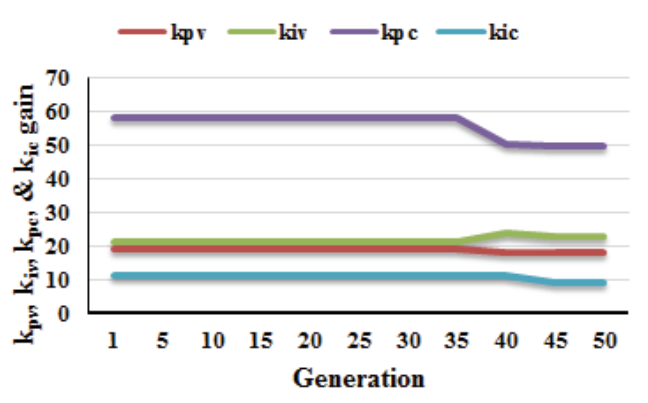

(a)

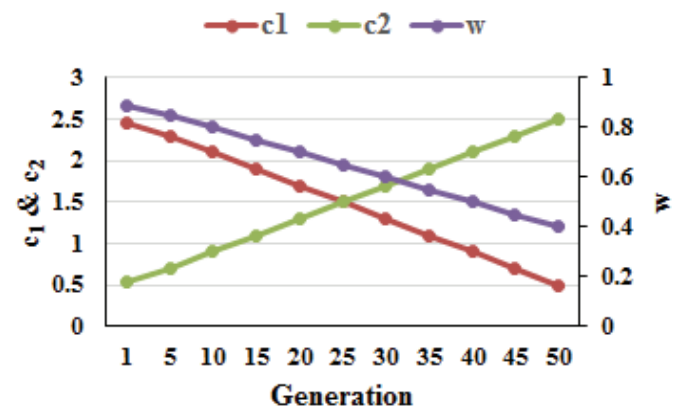

(b)

Fig. 10 (a) Controller gains variation in complete search process; (b) parametric variation in complete search process

generation, during $30-35^{\text {th }}$ generation it changes with value 85 . On $45^{\text {th }}$ generation, it again gets 85 value, the results show during $60-65^{\text {th }}$ generation, controller obtains 65 value. Finally, on $67^{\text {th }}$ generation, $k_{\text {ic }}$ settles with value 85 . The program terminates with combination of $\mathrm{k}_{\mathrm{pc}}, \mathrm{k}_{\mathrm{ic}}$ with 5.4 and 85 value respectively. All dynamic conditions are satisfied under specified constraints on $67^{\text {th }}$ generation and consumed $6.477 \mathrm{hr}$ in processing. This time includes the complete run time of the system with each set of controller gains. 
Table 4. Comparative results in various generations under proposed PSO approach

\begin{tabular}{|c|c|c|c|c|c|c|c|c|c|}
\hline \multirow{2}{*}{ Generation } & \multicolumn{5}{|c|}{ Voltage controller gain } & \multicolumn{4}{|c|}{ Current controller gain } \\
\hline & \multicolumn{2}{|c|}{$\mathrm{k}_{\mathrm{pv}}$} & \multicolumn{3}{|c|}{$\mathrm{k}_{\mathrm{iv}}$} & \multicolumn{2}{|l|}{$\mathrm{k}_{\mathrm{pc}}$} & \multicolumn{2}{|c|}{$\mathrm{k}_{\mathrm{ic}}$} \\
\hline $1-35$ & \multicolumn{2}{|c|}{19.195} & \multicolumn{3}{|c|}{20.976} & \multicolumn{2}{|c|}{58.26} & \multicolumn{2}{|c|}{11.019} \\
\hline $36-40$ & \multicolumn{2}{|c|}{18.23} & \multicolumn{3}{|c|}{23.82} & \multicolumn{2}{|c|}{50.01} & \multicolumn{2}{|c|}{11.019} \\
\hline $41-50$ & \multicolumn{2}{|c|}{18.23} & & \multicolumn{2}{|l|}{22.82} & \multicolumn{2}{|c|}{49.65} & \multicolumn{2}{|c|}{8.98} \\
\hline \multicolumn{10}{|c|}{ Power quality results variation in various generations } \\
\hline \multirow{2}{*}{ Dynamic Conditions } & \multicolumn{3}{|c|}{$\mathrm{PF}$} & \multicolumn{3}{|c|}{$\mathrm{THD}_{\mathrm{i}}(\%)$} & \multicolumn{3}{|c|}{$\left|\mathrm{V}_{\text {rp }}\right|$ p.u } \\
\hline & $1^{\text {st }}$ & $36^{\text {th }}$ & $50^{\text {th }}$ & $1^{\text {st }}$ & $36^{\text {th }}$ & $50^{\text {th }}$ & $1^{\text {st }}$ & $36^{\text {th }}$ & $50^{\text {th }}$ \\
\hline Load perturbation & 0.993 & 0.998 & 0.998 & 3.825 & 3.145 & 2.234 & 0.006 & 0.006 & 0.002 \\
\hline Voltage sag & 0.997 & 0.997 & 0.999 & 3.779 & 3.678 & 3.541 & 0.006 & 0.005 & 0.002 \\
\hline Non-linear load & 0.995 & 0.995 & 0.998 & 4.258 & 3.345 & 3.342 & 0.004 & 0.004 & 0.003 \\
\hline Tapped load fault & 0.998 & 0.998 & 0.999 & 3.975 & 2.956 & 2.659 & 0.006 & 0.005 & 0.004 \\
\hline Fault at phase $\mathrm{A}$ & 0.998 & 0.998 & 0.998 & 4.164 & 4.162 & 3.975 & 0.007 & 0.006 & 0.004 \\
\hline
\end{tabular}
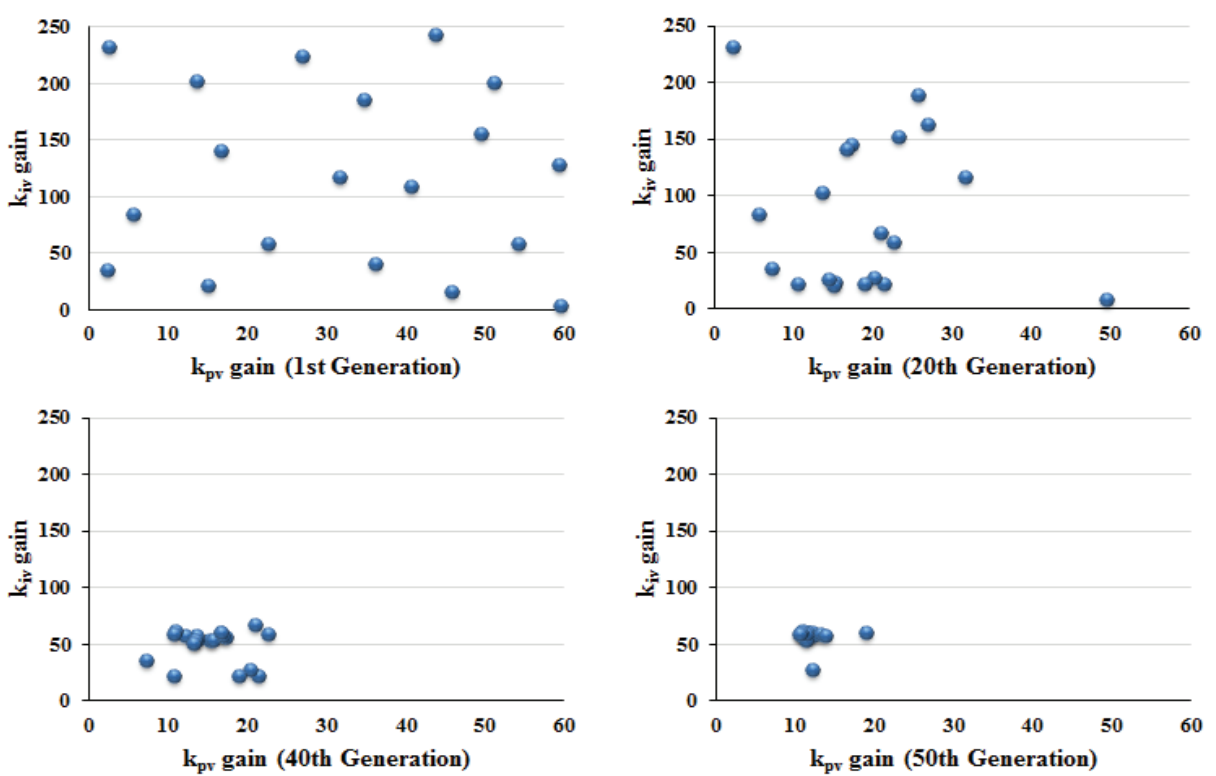

(a)
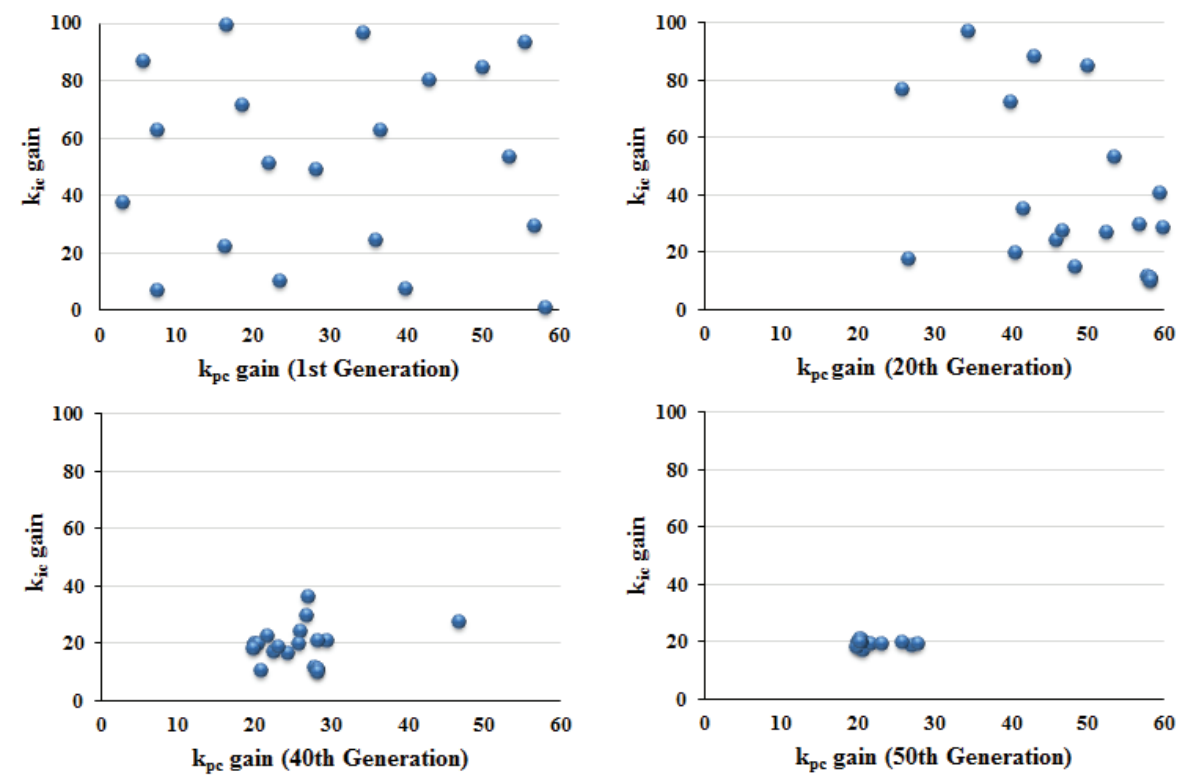

(b)

Fig. 11 Convergence of particles: (a) voltage controller gain; (b) current controller gain 
Table 5. Comparative outcome

\begin{tabular}{c|c|c|c}
\hline Conclusion & Zeigler-Nichols approach & Proposed GSS approach & Proposed PSO approach \\
\hline Outcome & $\begin{array}{c}\text { Calculate different controller gain for } \\
\text { different dynamic conditions }\end{array}$ & $\begin{array}{c}\text { Select common controller gain for } \\
\text { various dynamic conditions }\end{array}$ & $\begin{array}{c}\text { Select common controller gain for } \\
\text { various dynamic conditions }\end{array}$ \\
\hline Processing time & $\begin{array}{c}\text { Requires more time for manual tuning, } \\
\text { therefore time consuming }\end{array}$ & $\begin{array}{c}\text { Time consuming as it is successive linear } \\
\text { search }\end{array}$ & Consumed lesser time \\
\hline
\end{tabular}

\subsection{Performance evaluation using proposed PSO approach}

The proposed modifications e.g. exploration of complete search space, parametric variation of weighting factor and acceleration factors, and modified termination criteria output optimized controllers gain on $1^{\text {st }}$ generation. It consumed only $0.443 \mathrm{hr}$, however, to show effectiveness of the proposed algorithm, the program is run up to convergence of the particles and it consumes $8.33 \mathrm{hr}$ to converge all particles. Fig. 10(a) shows controllers gain variation in the complete search process, from $1^{\text {st }}$ to $35^{\text {th }}$ generation, the value of all controller gains remains unaltered, however, small variations from $36^{\text {th }}$ to $40^{\text {th }}$ generation in $\mathrm{k}_{\mathrm{pv}}, \mathrm{k}_{\mathrm{iv}}, \mathrm{k}_{\mathrm{pc}}$ controller gains are observed for seeking better results. Onwards, from $41^{\text {st }}$ to $50^{\text {th }}$ generations, variation in $\mathrm{k}_{\mathrm{pc}}$ i.e. 50.01 to 49.65 and variation in $k_{i c}$ i.e. 11.09 to 8.98 are observed. The parametric variation and controller gain convergence are presented in Fig. 10 and 11 respectively.

Table 4 reveals PQ results variations with respect to controllers gain. The controller gain variations are observed on $1^{\text {st }}, 36^{\text {th }}, 50^{\text {th }}$ generation. The improvements in results are obtained from $1^{\text {st }}$ generation to $50^{\text {th }}$ generation, however with small percentage in all dynamic cases. Therefore, it can be summarized that by using proposed PSO approach, complete converge of particles are not necessary as requires in conventional PSO approach. The proposed PSO approach gives quick response to dynamic conditions, thereby saves computer processing time.

The performance of 12-pulse VSC based HVDC system are evaluated using three different techniques under same operating conditions. Some observations are obtained while subjecting these techniques which are summarized in Table 5 .

\section{Conclusion}

The controller gain optimization for 12-pulse VSC based HVDC system has been presented in this paper. The three optimization techniques namely Ziegler Nichols, golden section search and particle swarm optimization have been applied simultaneously in the proposed system and compared their performances under same operating conditions such as load perturbation, non-linear load condition, voltage sag, tapped load fault at points-ofcommon coupling and single-line-to ground fault at input AC mains. The improved PQ results have been obtained with all techniques, however Ziegler Nichols calculated different controller gains for different dynamic conditions whereas proposed GSS and PSO selected common controller gain for all dynamic conditions. However, the proposed PSO technique showed better results as compared to GSS approach in terms of quick response to the dynamic conditions. Therefore, it can be concluded that the proposed PSO approach shall be used as an effective tool for searching optimum controller gains offline.

\section{Appendix 1}

HVDC system: 12-pulse VSC based HVDC system with $75 \mathrm{~km}$ long DC cable, PCC load: 100MW, 0.9 lagging PF, Line voltage: $230 \mathrm{kV}$, frequency: $50 \mathrm{~Hz}$, VSC switching frequency $=1950 \mathrm{~Hz}$, source impedance: $\mathrm{R}_{\mathrm{s}}=0.01 \Omega, \mathrm{L}_{\mathrm{s}}=$ 1.6mH. Transformer: $230 / 100 \mathrm{kV}$, impedance $r_{1}=r_{2}=r_{3}=$ $0.002 \mathrm{pu}, \mathrm{x}_{1}=\mathrm{x}_{2}=\mathrm{x}_{3}=0.02 \mathrm{pu}$, Interfacing reactance $=$ $0.336 \mathrm{H}, \mathrm{DC}$-link voltage: $190 \mathrm{kV}$, DC link capacitor: $\mathrm{C}_{\mathrm{dc}}=$ $350 \mathrm{mF}$.

GSS controlled controller gain:

$\mathrm{k}_{\mathrm{pv}}=3.8, \mathrm{k}_{\mathrm{iv}}=169 ; \mathrm{k}_{\mathrm{pc}}=85, \mathrm{k}_{\mathrm{ic}}=5.4$;

PSO controlled controller gain:

$$
\mathrm{k}_{\mathrm{pv}}=19.195, \mathrm{k}_{\mathrm{iv}}=20.976 ; \mathrm{k}_{\mathrm{pc}}=58.26, \mathrm{k}_{\mathrm{ic}}=11.019
$$

\section{Appendix 2}

\section{A. Selection of interfacing reactor}

The interfacing inductor is selected to limit $5^{\text {th }}$ order harmonic i.e. $20 \%$ of fundamental as required in conventional line commutated thyristor based HVDC system [25].

$$
\begin{array}{ll}
\text { Base impedance } & \mathrm{Z}_{\text {base }}=(\mathrm{kV})^{2} / \mathrm{MVA} \\
& \mathrm{X}_{\mathrm{L}}=0.2 \times \mathrm{Z}_{\text {base }} ; \mathrm{L}=\mathrm{X}_{\mathrm{L}} / 2 \pi \mathrm{f}
\end{array}
$$

The obtained value is $0.336 \mathrm{H}$.

\section{B. Selection of DC-link capacitor}

The DC-link capacitor acts as an energy buffer to stabilize DC-link ripple under normal as well as dynamic condition. The large value of capacitor may create 
harmonic distortion in input source and low value may cause instability in power balance. Therefore, selection of DC-link capacitor is important in VSC designing. The DClink capacitor is selected on number of basis such as power rating of VSC HVDC system, magnitude of DC link voltage, and recovery time under dynamic condition

For $100 \mathrm{MW}, 0.9 \mathrm{pf}$ load, total system rating $\mathrm{S}=\sqrt{ } \mathrm{P}^{2}+\mathrm{Q}^{2}$ $=112 \mathrm{MVA}$ with $48.42 \mathrm{MVar}$ reactive power. By considering safety factor, total rating is assumed 120MVA. The system is designed with full reactive power whereas $1.03 \%$ is considered for active power. Extra 3\% active power $(3 \mathrm{MW})$ is assumed for compensation provide by DC-link capacitor. In this system, it is desired to settle DC-link voltage within six cycles for $5 \%$ maximum overshoot or undershoot.

The DC-link capacitor is calculated as,

$$
\mathrm{E}=\mathrm{P} \cdot \Delta \mathrm{t}=(1 / 2) \cdot \mathrm{C}_{\mathrm{dc} .}\left\{\left(\mathrm{V}_{\mathrm{d}}{ }^{2}\right)^{2}-\left(\mathrm{V}_{\mathrm{d}}\right)^{2}\right\}
$$

Substituting values in Eqs (A3), $\mathrm{P}=3 \mathrm{MW}, \Delta \mathrm{t}=6 \times 20 \mathrm{~ms}$, $\mathrm{V}_{\mathrm{d}}=190 \mathrm{kV}, \mathrm{V}^{*}{ }_{\mathrm{d}}=184.3 \mathrm{kV}$, hence, $\mathrm{C}_{\mathrm{d}}$ is calculated as $337 \mathrm{mF}$, therefore, capacitor with $350 \mathrm{mF}$ value is selected by including safety factor.

\section{References}

[1] C. Du, E. Agneholm, G. Olsson, "Use of VSC-HVDC for Industrial Systems Having Onsite Generation with Frequency Control," IEEE Transactions Power Delivery, vol. 23, no. 4, pp. 2233-2240, Oct. 2008.

[2] N. Flourentzou, V. G. Agelidis, G. D. Demetriades, "VSC-Based HVDC Power Transmission Systems: An Overview," IEEE Transactions Power Electronics, vol. 24, no. 3, pp. 592-602, March 2009.

[3] Y. H. Liu, J. Arrillaga, N. R. Watson, "Addition of four-quadrant power controllability to multi-level VSC HVDC transmission," IET Generation, Transmission \& Distribution, vol. 1, no. 6, pp. 872-878, Nov. 2007.

[4] IEEE Recommended Practices and Requirement for Harmonics Control in Elect power System, IEEE Std. 519, 1992.

[5] B. Singh, V. Verma, A. Chandra, K. Al-Haddad, "Hybrid filters for power quality improvement," IEE Proceedings Generation, Transmission and Distribution, vol. 152, no. 3, pp. 365-378, 6 May 2005.

[6] M. Peterson, B.N. Singh, "Multipulse controlled ac$\mathrm{dc}$ converters for harmonic mitigation and reactive power management," IET Power Electronics, vol. 2, no. 4, pp. 443-455, July 2009.

[7] Y.H. Liu, J. Arrillaga, N.R. Watson, "A new highpulse voltage-sourced converter for HVDC transmission," IEEE Transactions Power Delivery, vol. 18, no. 4, pp. 1388-1393, Oct. 2003.

[8] D. Rivas, L. Moran, J.W. Dixon, J.R. Espinoza,
"Improving passive filter compensation performance with active techniques," IEEE Transactions Industrial Electronics, vol. 50, no. 1, pp. 161-170, Feb. 2003.

[9] Pang Hao, Wang Zanji, Chen Jianye, "Study on the Control of Shunt Active DC Filter for HVDC Systems," IEEE Transactions Power Delivery, vol. 23, no. 1, pp. 396-401, Jan. 2008.

[10] Aiguo Xu, Shaojun Xie. "A Multipulse-StructureBased Bidirectional PWM Converter for High-Power Applications," IEEE Transactions Power Electronics, vol. 24, no. 5, pp. 1233-1242, 2009.

[11] Pang Hao, Wang Zanji, Chen Jianye, "Study on the Control of Shunt Active DC Filter for HVDC Systems," IEEE Transactions Power Delivery, vol. 23, no. 1, pp. 396-401, Jan. 2008.

[12] J. Arrillaga, Y. H. Liu and N. R. Waston, Flexib le Power Transmission,The HVDC Option, John Wiley \& Sons Ltd, UK, Chichester. 2007.

[13] B.N. Singh, B. Singh, A. Chandra, P. Rastgoufard, K. Al-Haddad, "An Improved Control Algorithm for Active Filters," IEEE Transactions Power Delivery, vol. 22, no. 2, pp. 1009-1020, April 2007.

[14] N. Flourentzou, V.G. Agelidis, "Optimized Modulation for AC-DC Harmonic Immunity in VSC HVDC Transmission," IEEE Transactions Power Delivery, vol. 25, no. 3, pp. 1713-1720, July 2010.

[15] Dong Hae Yeom, Jin Bae Park, Young Hoon Joo, "Selection of coefficient for equalizer in optical disc drive by golden section search," IEEE Transactions Consumer Electronics, vol. 56, no. 2, pp. 657-662, May 2010.

[16] Ronnie F. Chu, Raul H. Avendano, "A Direct Method for Identifying the Optimal Power Factor Correction in Nonsinusoidal Systems," IEEE Transactions Power Apparatus and Systems, vol. PAS-104, no. 4, pp. 959964, July 1985.

[17] Changhe Li, Shengxiang Yang, Trung Thanh Nguyen, "A Self-Learning Particle Swarm Optimizer for Global Optimization Problems," IEEE Transactions Systems, Man, and Cybernetics, Part B: Cybernetics, vol. 42, no. 3, pp. 627-646, June 2012.

[18] S. Singh, B. Singh, "Optimized Passive Filter Design Using Modified Particle Swarm Optimization Algorithm for a 12-Pulse Converter-Fed LCI-Synchronous Motor Drive," IEEE Transactions Industry Applications, vol. 50, no.4, pp. 2681-2689, 2014.

[19] Zhi-Hui Zhan, Jun Zhang, Yun Li, Yu-hui Shi, "Orthogonal Learning Particle Swarm Optimization," IEEE Transactions Evolutionary Computation, vol. 15, no. 6, pp. 832-847, Dec. 2011.

[20] C.C. Hang, K.J. Astrom, W.K. Ho, "Refinements of the Ziegler-Nichols tuning formula," IEE Proceedings $D$ Control Theory and Applications, vol. 138, no. 2, pp. 111-118, 1991.

[21] N. Mohan, T.M. Undeland, and W.P. Robbins, Power Electronics, Converters, Applications and Design. 
New York: Third Edition, John Wiley \& Sons Inc, 2003.

[22] K. Ogata, "PID controllers and modified PID controllers," Modern control engineering ( $5^{\text {th }}$ edition), Pearson Education, India, pp. 568-572, 2010.

[23] Rao S. S. Optimization: theory and application. India:Willey Eastern Limited, 1978.

[24] N. Nayak, S. Mishra, S. Choudary, P. K. Rout, "Optimal design of VSC based HVDC system using Particle swarm otimization technique," in Proc of International conference on Power, Control and Embedded system, 2012, pp. 1-5.

[25] D.M. Mohan, B. Singh, K.B. Panigrahi, "Analysis and design of three-level, 24-pulse double bridge Voltage Source Converter based HVDC system for active and reactive power control," in Power Electronics, Drives and Energy Systems (PEDES) in 2010 Joint International Conference Power India, 2010, pp. 1-7, 2010.

Ruchi Agarwal was born in Kurukshetra, Haryana, India in 1980. She received the B.E (Electrical) degree from DCRUST, Murthal (Sonepat), Haryana, India in 2003, and the M.E (Electrical) degree from Punjab Engineering College (PEC), Chandigarh, India in 2007. She has completed her Ph.D degree in 2016 from Sant Longowal Institute of Engineering and Technology (SLIET), Longowal, Sangrur, Punjab. She joined Vikalp Solution, Noida as a SAP consultant in 2007, in 2009, she joined NIT Patna as an Assistant Lecturer on contractual basis. Her area of interest includes power electronics, power quality, high voltage direct current (HVDC) transmission system, and optimization.

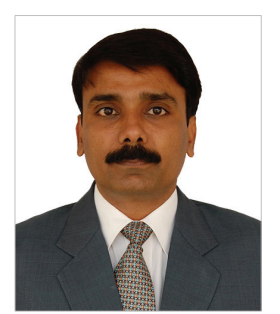

Sanjeev Singh, Associate Professor, Electrical and Instrumentation Engineering Department, Sant Longowal Institute of Engineering and Technology, Sangrur, Punjab received the B.E. (electrical) degree from Awadhesh Pratap Singh University (APSU), Rewa, M.P., India, in 1993, the M.Tech degree from Devi Ahilya Vishwa Vidyalaya (DAVV), Indore, M.P. India, in 1997, and the Ph.D. degree from the Indian Institute of Technology Delhi, New Delhi, in 2010. Before joining Longowal Institute of Engineering and Technology, Sangrur, Punjab, as Lecturer in Jan. 2000, he was with North India Technical Consultancy Organization Ltd. (NITCON), Chandigarh, as Project Officer, since Apr. 1997. There he was handling the industrial trouble shooting assignments along with consultancy in the area of energy management and renewable energy applications. He has published 65 research papers in various international and national journals and conferences including 06 papers in IEEE transactions. He has one Indian Patent filed to his credit. His areas of interest include power electronics, electrical machines and drives, DSP applications to power system and electric drives, Energy management, energy efficiency and power qualityDr. Singh is a Fellow of IETE (India) and IE (India), Senior Member of IEEE (USA) and Life Member of the Indian Society for Technical Education (LMISTE) and the System Society of India (LMSSI). 